\title{
Nicotinic Induction of Preproenkephalin and Tyrosine Hydroxylase Gene Expression in Butyrate-Differentiated Rat PC12 Cells: A Model for Adaptation to Gut-Derived Environmental Signals
}

\author{
BISTRA B. NANKOVA, JENNIFER CHUA, RAVI MISHRA, CATHERINE D. KOBASIUK, AND \\ EDMUND F. LA GAMMA \\ Division of Newborn Medicine, Departments of Pediatrics, Biochemistry, and Molecular Biology, New \\ York Medical College, The Regional Neonatal Center, Westchester Medical Center, Valhalla, New York, \\ U.S.A.
}

\begin{abstract}
Accelerated maturation of peripheral sympathoadrenal transmitter levels and function occurs at 7-10 postnatal days in the rat. This event is temporally disconnected from the timing of major changes in physiologic stimuli evident after the birthing process (i.e. temperature, oxygen, sound, light, etc.). Colonization of the gut, fermentation of carbohydrates, and production of short-chain fatty acids (e.g. butyrate) mirrors this postnatal time course. In this report, we examined the interaction between butyrate differentiation of rat pheochromocytoma cells and cholinergicnicotinic induction of the neuropeptide (enkephalin) and catecholamine-related biosynthetic enzymes (tyrosine hydroxylase, dopamine $\beta$-hydroxylase, phenylethanolamine $N$-methyltransferase). Our results show that butyrate induces both preproenkephalin and tyrosine hydroxylase mRNA through a proximal promoter region and that this regulatory step is time and dose dependent. Moreover, there is an additional interaction with cholinergic-nicotinic inducible mechanisms consistent with classically described transsynaptic cholinergic regulation of these genes. Dopamine $\beta$-hydroxylase and phenylethanolamine $N$ -
\end{abstract}

\section{ABSTRACT}

methyltransferase promoters were not affected by butyrate treatment. We speculate that colonization of the human gut (along with the attendant fermentation of enteral carbohydrates to shortchain fatty acids) may represent a mechanism through which environmental signals affect postnatal maturation of sympathoadrenal transmitter systems. (Pediatr Res 53: 113-118, 2003)

ppENK, preproenkephalin

pRPE2, enkephalin gene coding sequence plasmid pREJCAT, enkephalin promoter reporter plasmid

TH, tyrosine hydroxylase

DBH, dopamine $\beta$-hydroxylase

PNMT, phenylethanolamine N-methyltransferase

CAT, chloramphenicol acetyltransferase

PC12, rat pheochromocytoma

SCFA, short-chain fatty acids

NaBtr, sodium butyrate
Circulating catecholamines and endogenous opioid peptides arise primarily from the adrenal medulla $(1,2)$, where they are co-stored and co-released from chromaffin cells (3). In rats, between 7 and 10 days of postnatal life, adrenal transmitter biosynthetic and release mechanisms mature to adult capacity in response to progressive cholinergic innervation, and as a result of the influences of the hypothalamic-pituitary-adrenal

Received October 4, 2001; accepted July 4, 2002.

Correspondence: Edmund F. La Gamma, Division of Newborn Medicine, Departments of Pediatrics, Biochemistry, and Molecular Biology, New York Medical College, and the Regional Neonatal Center, Westchester Medical Center, Valhalla, NY 10595, U.S.A.; e-mail: edmund_lagamma@nymc.edu

Supported by NYMC/WMC institutional grants.

DOI: 10.1203/01.PDR.0000039764.38034.75 cortical and thyroid hormonal systems (4-13). Because a progressive rise in systemic blood pressure and autonomic reflex responsiveness is well characterized in the first postnatal week in humans (11), similar control mechanisms are thought to apply. Paradoxically, it is well recognized that adrenal transmitter systems can adapt rapidly to change steady-state levels of transmitter-related mRNA in as little as a few hours, not typically a few days (14-17). Thus, maturational delays occurring up to 2 weeks after birth portend the existence of other more gradually acquired regulatory signals, perhaps even an environmental signal.

SCFA (i.e. acetate, propionate, and butyrate) are widely recognized as progressively accumulated by-products of postnatally acquired enteric bacterial carbohydrate fermentation in 
the first postnatal week (18). Absorbed SCFA blood levels achieved in the portal and systemic circulations can be as high as $2 \mathrm{mM}$ (19). Moreover, the timing of bacterial colonization and fermentation is coincident with the 7- to 10-days maturational cascade of the sympathoadrenal system (19). In view of this, we hypothesized that both SCFA and classical cholinergic developmental mechanisms may interact to influence adrenal transmitter biosynthesis.

To test this hypothesis, we chose a rat pheochromocytoma cell model system (PC12 cells). Morphologically, PC12 cells resemble chromaffin cells at a late fetal stage of development. These cells display noradrenergic phenotype and have low, almost undetectable, levels of enkephalin mRNA similar to immature adrenal chromaffin cells (20). PC12 cells also exhibit plasticity, retaining the ability to differentiate into cells resembling sympathetic neurons upon addition of nerve growth factor and other related effector molecules (20-23). They can also be made to mature into chromaffin-like cells in vitro in the presence of glucocorticoids (4). Lastly, SCFA (i.e. butyrate) have long been known to differentiate PC12 cells into chromaffin-like cells as well as to elevate levels of TH (EC 1.14.16.2) and enkephalin mRNA (24-26). Therefore, the purpose of this study was to investigate the molecular mechanisms regulating TH and ppEnk gene expression during butyrate differentiation of $\mathrm{PC} 12$ cells along with the concomitant stimulation of cholinergic receptors with nicotine.

\section{METHODS}

PC12 cells. The PC12 cell line used in the experiments was obtained from Simon Halegoua (Department of Neurobiology and Behavior, State University of New York, Stony Brook, NY, U.S.A.) and originally established by Lloyd Greene (20). Cells were maintained in Dulbecco's modified Eagle's medium supplemented with $10 \%$ horse serum, $5 \%$ fetal bovine serum, $50 \mu \mathrm{g} / \mathrm{mL}$ streptomycin, and $50 \mathrm{IU} / \mathrm{mL}$ penicillin in a humidified atmosphere at $37^{\circ} \mathrm{C}$ and $10 \% \mathrm{CO}_{2}$. They were grown to a density of approximately $6 \times 10^{7}$ cells per $100 \mathrm{~mm}$ Petri dish and then split 1:5 approximately every $5 \mathrm{~d}$. Two days before confluence, PC12 cells were treated with 1 or $6 \mathrm{mM} \mathrm{NaBtr}$ in media. After incubating for $1 \mathrm{~d}$, cells were treated with nicotine for varying lengths of time or doses of the drug. For nicotine treatment, nicotine di-tartarate solution (Sigma Chemical, St. Louis, MO, U.S.A.) was prepared in sterile water and added at the desired final concentrations. At indicated times, the cells were harvested for assay. Cells treated with $\mathrm{NaBtr}$ continued to receive media supplemented with NaBtr during nicotine treatment.

DNA-mediated transfection and reporter gene assay. CAT reporter plasmids containing 5 ' upstream promoter sequences from rat proenkephalin, TH, DBH (EC 1.14.17.1), and PNMT (EC 2.1.1.28) genes were used in these experiments. The proenkephalin promoter construct derived from -1050 enkephalin promoter reporter plasmid (27) and contained (-841/ $+53) \mathrm{bp}$ of the rat proenkephalin promoter fused to the CAT reporter gene. The TH promoter construct contained ( $-773 /$ +27) bp of the rat TH gene driving the expression of the CAT reporter and was a gift from E. Lewis (28). PNMT promoter construct had the first $-877 /+8$ bp of the rat PNMT gene subcloned into a CAT reporter vector (29). The DBH promoter construct contained approximately $1 \mathrm{~kb}$ from the upstream promoter region of the rat $\mathrm{DBH}$ gene fused to a CAT reporter gene (30). All plasmids were prepared by $\mathrm{CsCl}$ gradient centrifugation or by chromatography on QIAGEN columns (QIAGEN, Valencia, CA, U.S.A.).

One day before confluence, PC12 cells were either left untreated (controls) or treated with $\mathrm{NaBtr}$ in media. After incubating for $1 \mathrm{~d}$, all cells were electroporated at $300 \mathrm{~V}$ and $500 \mu \mathrm{F}$. Each $100 \mathrm{~mm}$ plate containing $10^{6}-10^{7}$ cells was transfected with $20 \mu \mathrm{g}$ of plasmid. After the indicated amount of time, the cells were harvested and protein concentration in total cell lysates was determined (31). Aliquots with equal amounts of protein were assayed for reporter gene activity. CAT activity was determined by a liquid scintillation method with ${ }^{3} \mathrm{H}$-chloramphenicol (32). Comparisons between controls and butyrate-treated transfected cells, performed in triplicate from the same experiment, with the same promoter construct plasmid DNA were performed.

Isolation of RNA and Northern blot analysis. Total RNA was extracted using minor modifications of the acid guanidinium thiocyanate phenol chloroform method and quantified by UV spectroscopy as previously described (33). Ten micrograms of total RNA were fractionated on a glyoxal denaturing gel, electrotransferred to nylon filter (Biotrans nylon membrane, ICN Company, CA, U.S.A.), UV cross-linked, baked for $2 \mathrm{~h}$ at $80^{\circ} \mathrm{C}$, and prehybridized overnight. Prehybridizing and hybridizing conditions were as previously described (33).

Each RNA blot was hybridized at $45^{\circ} \mathrm{C}$ to a radiolabeled, double-stranded fragment of rat ppEnk cDNA, enkephalin gene coding sequence plasmid [kindly provided by S. Sabol (34)] for 24-48 h. A Pvull digest of enkephalin gene coding sequence plasmid yielded a 435-bp exon 3 fragment, which was labeled with 32-P 2'-deoxycytidine 5'-triphosphate to a specific activity of $>10^{9} \mathrm{cpm} / \mu \mathrm{g}$ using a random primer labeling kit (Prime-it; Stratagene, La Jolla, CA, U.S.A.) was used in this experiments. After each hybridization, the blots were washed at $60^{\circ} \mathrm{C}$ in $0.2 \times \mathrm{SSC} / 0.1 \% \mathrm{SDS}$ for $30 \mathrm{~min}$, again at $50^{\circ} \mathrm{C}$, and then autoradiographed. After washing and autoradiography, results from our studies were quantified by two-dimensional scanning densitometry using a LKB 2400 Gelscan XL apparatus (LKB, Uppsala, Sweden). Digitized data were analyzed with LKB Gelscan 1.0. Multiple exposures of the same experiments were analyzed so that band or spot intensities used for analysis represent subsaturation values.

Blots were rehybridized consecutively to a Pst I $1085-\mathrm{bp}$ fragment of glyceraldehyde-3-phosphate dehydrogenase $\mathrm{pR}$ GAPDH-13 as a RNA loading control [kindly provided by K.B. Marcu (35)], or to a Kpnl-Pstl 282-bp fragment of the plasmid $\mathrm{pTH}-4$, which contains the coding region for the rat TH gene [kindly provided by E. Lewis, Oregon Health Sciences University, Portland, OR, U.S.A. (25)].

Statistical analysis. Statistical significance was determined by $t$ test for experiments with two groups or by performing an ANOVA followed by Fisher's least significant difference test for experiments with more than two groups. A level of $p<$ 0.05 was accepted as statistically significant. 


\section{RESULTS}

Time course of proenkephalin gene induction by butyrate. It has been previously shown that $\mathrm{NaBtr}$ in a wide range of concentrations $(0.1-6 \mathrm{mM})$ efficiently stops cell division and promotes chromaffin-like differentiation of PC12 cell (36). Because it is unstable in the media $(24,36)$, the highest concentration is usually used. The kinetics of mRNA accumulation in $\mathrm{PC} 12$ cells treated with $\mathrm{NaBtr}$ also appear to be gene-specific, where a rapid rise in $c$-fos mRNA occurs within minutes while $c$-jun mRNA is elevated only after $24 \mathrm{~h}$ of treatment (37).

To determine the effects of butyrate in our system we first examined the time course of induction of proenkephalin mRNA in PC12 cells in response to a $6 \mathrm{mM}$ concentration; a dose previously reported to induce enkephalin expression (24). Cells were treated with the drug and at the indicated time points total RNA was isolated and the relative levels of proenkephalin mRNA were determined by Northern blot analysis (Fig. 1). The steady state levels of proenkephalin mRNA were barely detectable in control, untreated cultures. During the course of several experiments, the maximal effect of a 2- to 5 -fold elevation occurred between 40 and $48 \mathrm{~h}$ of treatment, followed by a decline to nearly half that level by $80 \mathrm{~h}$. Trypan blue exclusion indicated that the observed decrease in proenkephalin mRNA levels at later time points was not due to cell death. In untreated cultures, the steady state levels of ppEnk mRNA remained constant over the same time period. Rehybridization of the same filters with another cDNA probe encoding the house keeping gene glyceraldehyde-3-phosphatedehydrogenase revealed that butyrate treatment did not cause a statistically significant change in its expression. These results were consistent with previous findings (37) that butyrate is acting on selected PC12 cell "target" genes rather than causing a generalized activation of transcription.

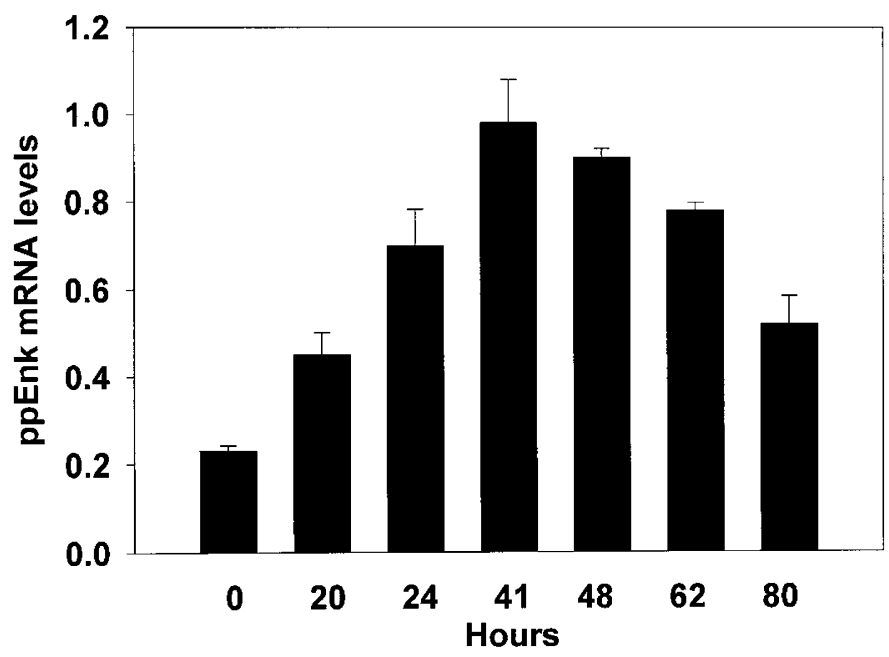

Figure 1. Kinetics of ppEnk gene induction by NaBtr in PC12 cells. Replicate (triplicate) cultures were incubated in culture media supplemented with $6 \mathrm{mM} \mathrm{NaBtr}$. At the times indicated, media were aspirated and total RNA isolated and subjected to Northern blot analysis as described in "Methods." The mRNA values are reported as mean \pm SEM and are an average of 5-10 culture plates.

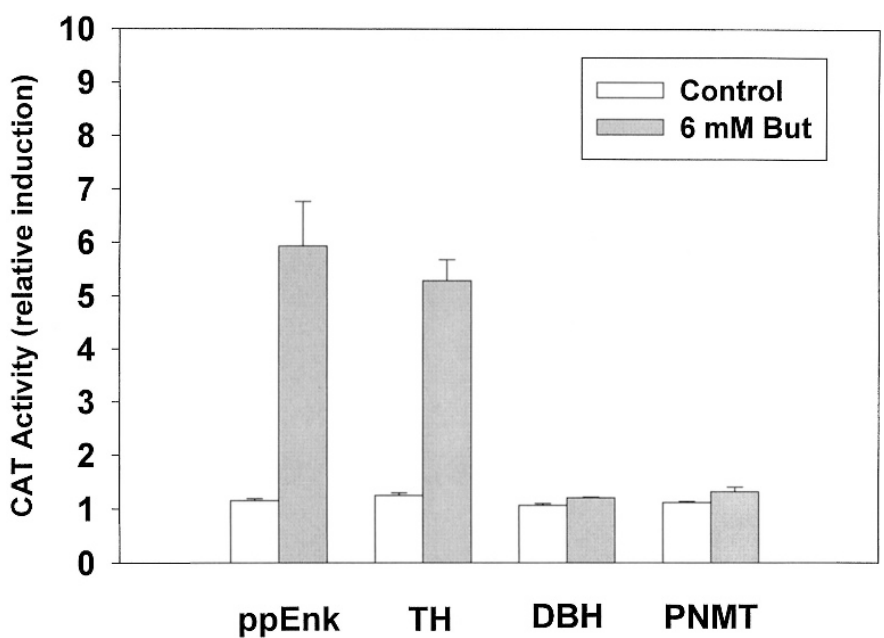

Figure 2. Transcriptional activation of ppEnk gene by NaBtr. Plasmid constructs with proenkephalin promoter (ppEnk) as well as rat $\mathrm{TH}, \mathrm{DBH}$, and PNMT promoters, linked to the CAT reporter gene were transfected in PC12 cells in the absence or presence of $6 \mathrm{mM} \mathrm{NaBtr}$ ( $24 \mathrm{~h}$ treatment). Cell extracts were prepared after another $24 \mathrm{~h}$ and assayed for CAT activity. Equivalent amounts of protein were used in each assay. CAT activities of untreated control cells were set to 1.0. Activities of NaBtr-treated cells are expressed as fold induction of the corresponding controls. All data are means \pm SEM of three independent experiments performed with 5-10 replica plates for each construct. $* p \leq 0.05$ compared with its own control.

The effect of NaBtr on proenkephalin gene expression is mediated through its promoter. The rise in steady state mRNA levels may result from increased synthesis, decreased degradation (turnover), or both mechanisms. Therefore, it was important to determine whether butyrate could enhance transcription from the ppEnk promoter in a DNA-mediated transient expression assay. In these experiments, control (untreated) and butyrate-differentiated PC12 cells were transfected by electroporation with a construct in which a CAT reporter gene was driven by an upstream segment $(-841 /+53 \mathrm{bp})$ of the rat proenkephalin promoter (Fig. 2). The relative CAT reporter gene activity was increased about 5 -fold in cultures treated with butyrate, suggesting that the observed rise in the relative abundance of endogenous ppEnk mRNA involves transcriptional activation of the native gene.

To distinguish between a general effect of $\mathrm{NaBtr}$ on plasmid uptake or stability in these transient transfection and transcriptional activation experiments, several other promoter constructs were analyzed. In these studies, rat TH, DBH, or PNMT promoters preceded the CAT reporter gene. Butyrate caused a similar induction of CAT activity under the control of rat TH promoter. In contrast, under the same conditions, no statistically significant changes in reporter activity were observed under the control of rat DBH or PNMT promoters (Fig. 2). Inasmuch as the constructs used in these experiments differed only by the particular promoter sequence, driving the expression of CAT, the observed selective induction of transcription of only TH and ppEnk is unlikely to reflect a general effect of butyrate on plasmid uptake or stability $(38,39)$. These data suggest that only specific target genes are able to provide a transcriptional response to the differentiation agent butyrate.

Dose-dependent effects of NaBtr. To determine whether effects were dose dependent, PC12 cells were treated with 1 or 
$6 \mathrm{mM} \mathrm{NaBtr}$ for $48 \mathrm{~h}$, and the relative abundance of ppEnk and TH mRNA was again determined by Northern blot analysis (Fig. 3). Both concentrations of butyrate resulted in a statistically significant elevation in the relative levels of ppEnk mRNA. In contrast, the expression of TH mRNA was upregulated only in response to $1 \mathrm{mM} \mathrm{NaBtr}$; the higher concentration of butyrate resulted in levels of TH mRNA decreasing below those in control (i.e. untreated) cultures. Thus, depending on the dose, butyrate may exert differential effect on the expression of ppEnk and TH genes.

Differential regulation of ppEnk and TH gene expression in butyrate-treated PC12 cells by nicotine. It has been previously shown that nicotine treatment of cells of adrenomedullary origin ( $\mathrm{PC} 12$ cells or bovine chromaffin cells) increases the expression of neurotransmitter related genes like TH (4045). Nicotine treatment (24-h exposure on d 3-4) caused a further increase in the relative abundance of ppENK mRNA above that observed after butyrate treatment alone at both concentrations of nicotine used (50 and $100 \mu \mathrm{M})$ and at either concentration of butyrate ( 1 or $6 \mathrm{mM}$; Fig. 4). At low butyrate concentration $(1 \mathrm{mM})$, either concentration of nicotine augmented the accumulation of TH mRNA. However, at the higher concentration of butyrate $(6 \mathrm{mM})$, cholinergic receptor stimulation did not increase TH mRNA; in fact, it even decreased TH mRNA levels further (and more so at higher nicotine doses; Fig. 4). Thus, under the same conditions, the expression of TH mRNA is apparently subjected to a different mechanism of control.

\section{DISCUSSION}

The present study was undertaken to achieve a better understanding of the molecular mechanism(s) responsible for regulation of neurotransmitter gene expression in the developing rat autonomic nervous system in the immediate postnatal period. We examined the regulation of the expression of the ppEnk

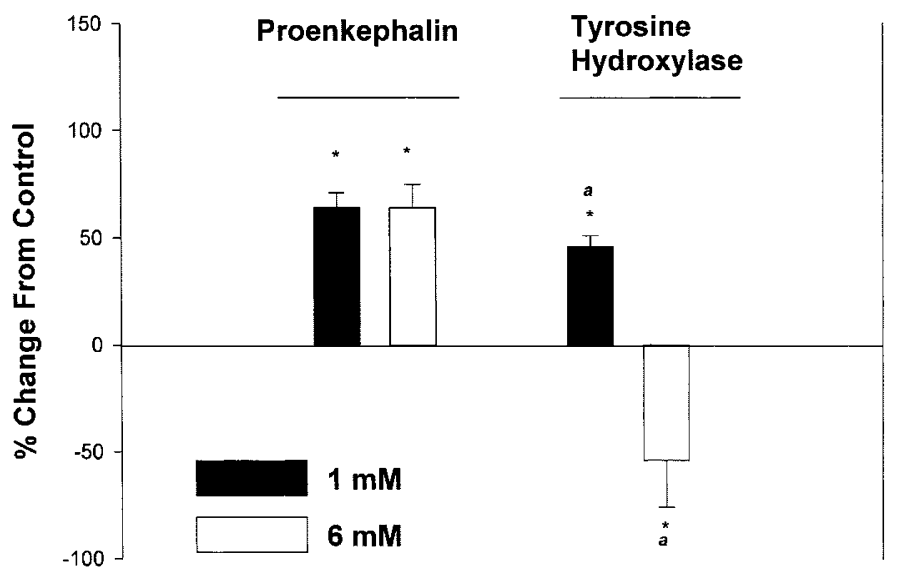

${ }^{*} p<0.05$ vs control

a $p<0.05$ vs each other

Figure 3. Butyrate effects in PC12 cells are dose dependent and gene specific. Cells were plated as described and left untreated or induced with $1 \mathrm{mM}$ or 6 $\mathrm{mM} \mathrm{NaBtr}$ for $48 \mathrm{~h}$. The relative levels of ppEnk and TH mRNA were determined by Northern blot analysis. The data are presented as mean \pm SEM values of mRNA levels relative to those in untreated cells. ${ }^{*} p \leq 0.05$ compared with controls.

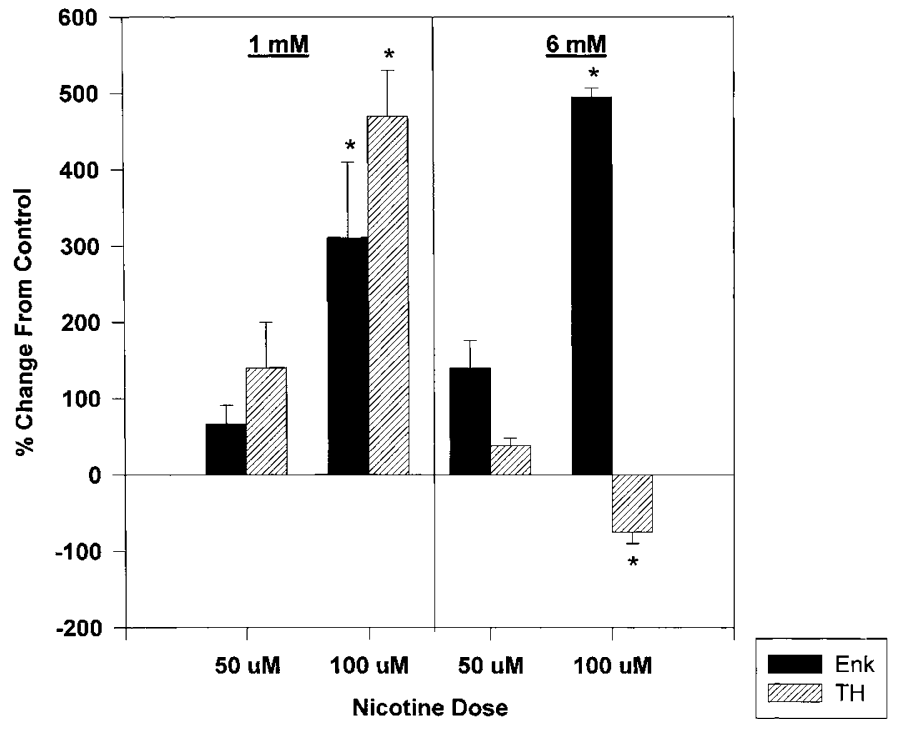

Figure 4. Effects of nicotine on ppEnk and TH mRNA levels in butyratedifferentiated PC12 cells. PC12 cells were induced with 1 or $6 \mathrm{mM} \mathrm{NaBtr}$ for $24 \mathrm{~h}$. Nicotine in two different concentrations, $50 \mu \mathrm{M}$ and $100 \mu \mathrm{M}$, was added than to half of the cultures. The cells were harvested $24 \mathrm{~h}$ after nicotine treatment and the relative abundance of ppEnk and TH mRNA determined by Northern blot analysis. Significant alterations in mRNA levels compared with the corresponding butyrate control are indicated $(* p \leq 0.05)$.

gene as an opiate marker of neuropeptide transmitter synthesis and $\mathrm{TH}$ gene expression as a marker for catecholamine biosynthesis during butyrate-elicited differentiation of $\mathrm{PC} 12$ cells. Treatment with a higher dose of NaBtr $(6 \mathrm{mM})$ caused a delayed elevation in the steady state levels of ppEnk mRNA; maximal at $48 \mathrm{~h}$ after addition of the compound (Fig. 1). Whereas $c$-fos and c-jun mRNA remained maximally elevated in $\mathrm{PC} 12$ cells during the continual presence of $\mathrm{NaBtr}$ in the medium for at least $72 \mathrm{~h}$ (37), we found a significant decrease in the relative ppEnk mRNA levels at later time points. The changes in the relative abundance of ppEnk mRNA could be due to either transcriptional or nontranscriptional (e.g. stabilization) events.

Our in vitro transfection experiments indicate that the ppEnk gene is regulated at the transcriptional level. The 5' upstream region of the rat $\mathrm{TH}$ gene was also able to confer elevated reporter gene expression in response to butyrate (Fig. 2). These observations are consistent with a transcriptional up-regulation of both the ppEnk and the TH genes in butyrate-differentiating PC12 cells. The precise molecular mechanisms mediating the effects of butyrate on neurotransmitter gene expression are largely unknown. Butyrate has been reported to modulate the transcription of a small fraction (about 2\%) of the genes, expressed in cultured tumor cells, and its action has traditionally been attributed to reversible inhibition of histone deacetylases. These include both gene activation and gene silencing events $(46,47)$. Consistent with these data, we did not find changes in the transcription of two other genes involved in the biosynthesis of catecholamines (DBH and PNMT) after butyrate treatment (Fig. 2).

We also obtained evidence that NaBtr may have no effect or can either increase or decrease expression of specific target 
genes depending on the dose used. Although both doses of the drug used in our experiments were equally effective in inducing ppEnk gene expression, TH mRNA accumulated only in cultures treated with a low dose of the compound $(1 \mathrm{mM})$. A similar rise in steady state TH mRNA levels, elicited by $1 \mathrm{mM}$ butyrate was also observed by others (25). In contrast, we found that the higher dose of this SCFA $(6 \mathrm{mM})$ resulted in a significant decrease in the relative abundance of TH mRNA (Fig. 3). Such down-regulation of TH mRNA levels in PC12 cells has also been reported by others (26) and may well have biologic significance during states of high circulating levels of SCFA (i.e. ketoacidosis, starvation). Down-regulation of TH gene expression in the adrenal medulla by products of lipid and carbohydrate metabolism may also contribute to the blunted epinephrine responses characteristic of hypoglycemia associated autonomic failure $(48,49)$.

It is well established that cholinergic receptor modulation of transmitter genes is an important maturational factor affecting transmitter expression in the developing autonomic nervous system (5). In the present study, we used a butyratedifferentiated PC12 cell model system to study the regulation of ppEnk and TH gene expression by nicotine. Nicotiniccholinergic stimulation augmented the effects of butyrate on endogenous or ppEnk reporter gene expression in PC12 cells in all experimental paradigms studied (Fig. 4). Because nicotinic stimulation of cholinergic receptors is coupled to activation of several signaling pathways, including protein kinase $\mathrm{C}, \mathrm{Ca}^{2+} /$ calmodulin-dependent protein kinases, and/or protein kinase $\mathrm{A}$ $(41,43,50-52)$, one can speculate that one or more of these second messengers and their respective cis-acting promoter elements are used by butyrate to elevate the transcription of the ppEnk gene.

When the catecholamine pathway was examined, at the lower butyrate concentration $(1 \mathrm{mM})$, nicotinic agonist treatment resulted in a concentration-dependent enhancement of $\mathrm{TH}$ expression in this system. In contrast, at the higher concentration of butyrate $(6 \mathrm{mM})$, nicotine either did not affect or further potentiated the down-regulation of $\mathrm{TH}$ gene expression. Thus, our current and previous data (53) suggest that an independent (perhaps divergent) regulation of the neuropeptide proenkephalin and the rate-limiting enzyme in catecholamine biosynthesis, TH, exists under the combined influence of SCFA and nicotinic-cholinergic signals.

Previous reports have shown that the SCFA acetate, propionate, and especially butyrate produced by microbial fermentation of dietary carbohydrate in the large intestine [molar ratio in humans 57:22:21 (54)] play a physiologic role as regulators of pathways of colonic epithelial cell maturation, cell cycle arrest, lineage-specific differentiation, and apoptosis $(19,55-$ 58). Butyrate concentrations in cecal fluid and colonic contents of rats, pigs, and monkeys has been reported to vary from 3 to $7 \mathrm{mmol} / \mathrm{L}$ to as high as $40 \mathrm{mmol} / \mathrm{L}$ depending on the $\operatorname{diet}(59)$. Similarly, in humans, the reported SCFA values are entirely dependent on gut flora, carbohydrate substrate, and postnatal age, but are much lower than in rodents or ruminants $(19,54)$. Moreover, $60 \%$ of absorbed SCFA' from the human gut are metabolized in the liver before being distributed to the body for various other functions in metabolic and regulatory pathways.
Once in the circulation, the molar ratio of SCFA differ from colonic levels with a decrease in the relative amounts of propionate and butyrate [human blood actetate:propionate:butyrate ratio 91:5:4 (54)]. Their possible function as an external regulatory signal is plausible because even low levels of SCFA share the ability to induce, for example, gamma-globin gene expression (60). Naturally occurring gut-derived compounds and their derivatives have been used pharmacologically in humans for treatment of beta-chain hemoglobinopathies as well as ulcerative colitis (61). Taken together, these data suggest a role for SCFA in normal as well as abnormal human biology. The data in our present report are consistent with an extended role of SCFA as gut-derived exogenous regulatory signals for the developing nervous system.

The postnatal maturation of the sympathoadrenal transmitter system during the first postnatal week coincides with the process of gut colonization and a rise in diet-derived plasma levels of SCFA $(18,19)$. Moreover, because the blood content of SCFA in rats is found to be at least 1-2 $\mathrm{mM}(62)$, its in vivo effect is in the physiologic range with the concentrations of butyrate used in our in vitro study. Therefore, it is attractive to speculate that plasma butyrate may act as a postnatal humoral regulatory factor in vivo by aiding maturation of the autonomic nervous system through an interaction with the more classically defined cholinergic (transsynaptic nicotinic) mechanisms.

In conclusion, our results make use of butyrate-differentiated PC12 cells as a model system for studying the molecular regulatory mechanisms governing postnatal maturation of neurotransmitter synthesis in the autonomic nervous system as influenced by either butyrate or nicotine. The effects of butyrate are gene-specific, involve transcriptional activation, and depend on the concentration and timing of drug. From a physiologic perspective, both catecholamine-dependent cardiovascular responses and endogenous opiate analgesic stress responses may be affected by prior exposure to cholinergic activity and the presence of gut-derived SCFA. We speculate that cholinergic receptor pathways linked to nicotinic receptor second messenger systems interact with upstream regulatory elements in ppEnk and TH genes to modulate the phenotypic neurotransmitter expression in butyrate-differentiated PC12 cells. Moreover, our data support the intriguing hypothesis that colonization of the gut (from maternal vaginal flora or the neonatal environment) with its attendant fermentation of carbohydrate (milk) represents a postnatally acquired maturational signal derived from a mammal's environment after birth.

Acknowledgments. The authors thank Drs. Joseph DeCristofaro, Marian Evinger, Esther Sabban, Gary Weisinger, and Pradeep Mally for stimulating conversations and suggestions during the conduct of this work. We also thank Drs. E. Lewis, E. Sabban, and M. Evinger for use of their TH, DBH, and PNMT promoter constructs.

\section{REFERENCES}

1. Bastiaensen E, De Block J, De Potter WP 1988 Neuropeptide Y is localized together with enkephalins in adrenergic granules of bovine adrenal medulla. Neuroscience 25:679-686 
2. Fischer-Colbrie R, Iacangelo A, Eiden LE 1988 Neural and humoral factors separately regulate neuropeptide $\mathrm{Y}$, enkephalin, and chromogranin $\mathrm{A}$ and $\mathrm{B}$ mRNA levels in rat adrenal medulla. Proc Natl Acad Sci U S A 85:3240-3244

3. Lundberg JM, Hokfelt T 1983 Coexistence of peptides and classical neurotransmitters. Trends Neurosci 6:325-333

4. Anderson DJ, Axel R 1986 A bipotential neuroendocrine precursor whose choice of cell fate is determined by NGF and glucocorticoids. Cell 47:1079-1090

5. Hamill RW, Gamma EFL 1992 Autonomic nervous system development. In: Bannister SR (ed) Autonomic Failure: A Textbook of Clinical Disorders of the Autonomic Nervous System. Oxford University Press, New York, pp 15-35

6. La Gamma EF, De Cristofaro JD, Agarwal BL, Weisinger G 1989 Ontogeny of the opiate phenotype: an approach to defining transsynaptic mechanisms at the molecular level in the rat adrenal medulla. Int J Dev Neurosci 7:499-511

7. LaGamma EF, White JD, McKelvy JF, Black IB 1987 Increased cAMP or $\mathrm{Ca}^{++}$ second-messengers reproduce effects of depolarization on adrenal enkephalin pathways. Ann N Y Acad Sci 493:270-272

8. Lau C, Ross LL, Whitmore WL, Slotkin TA 1987 Regulation of adrenal chromaffin cell development by the central monoaminergic system: differential control of norepinephrine and epinephrine levels and secretory responses. Neuroscience 22:10671075

9. Lau C, Franklin M, McCarthy L, Pylypiw A, Ross LL 1988 Thyroid hormone control of preganglionic innervation of the adrenal medulla and chromaffin cell development in the rat. An ultrastructural, morphometric and biochemical evaluation. Brain Res Dev Brain Res 44:109-117

10. Lillien LE, Claude P 1985 Nerve growth factor is a mitogen for cultured chromaffin cells. Nature 317:632-634

11. Slotkin TA 1985 Developmental Neurobiology of the Autonomic Nervous System. Humana Press, Totowa, NJ, pp 69-133

12. Ungar A, Phillips JH 1983 Regulation of the adrenal medulla. Physiol Rev 63:787843

13. Weisinger G 1995 The transcriptional regulation of the preproenkephalin gene. Biochem J 307:617-629

14. Henion PD, Landis SC 1993 Modulation of the enkephalinergic phenotype of rat sympathetic neurons by hormonal and transsynaptic mechanisms. J Neurobiol 24:1243-1251

15. Kanamatsu T, Unsworth CD, Diliberto Jr EJ, Viveros OH, Hong JS 1986 Reflex splanchnic nerve stimulation increases levels of proenkephalin A mRNA and proenkephalin A-related peptides in the rat adrenal medulla. Proc Natl Acad Sci U S A 83:9245-9249

16. Kvetnansky R, Sabban EL 1998 Stress and molecular biology of neurotransmitterrelated enzymes. Ann N Y Acad Sci 851:342-356

17. Sabban EL, Kvetnansky R 2001 Stress-triggered activation of gene expression in catecholaminergic systems: dynamics of transcriptional events. Trends Neurosci 24:91-98

18. Szylit O, Maurage C, Gasqui P, Popot F, Favre A, Gold F, Borderon J 1998 Fecal short-chain fatty acids predict digestive disorders in premature infants. JPEN J Parenter Enteral Nutr 22:136-141

19. Topping DL, Clifton PM 2001 Short-chain fatty acids and human colonic function: roles of resistant starch and nonstarch polysaccharides. Physiol Rev 81:1031-1064

20. Greene LA, Tischler AS 1976 Establishment of a noradrenergic clonal line of rat adrenal pheochromocytoma cells which respond to nerve growth factor. Proc Natl Acad Sci USA 73:2424-2428

21. Claude P, Parada IM, Gordon KA, D'Amore PA, Wagner JA 1988 Acidic fibroblast growth factor stimulates adrenal chromaffin cells to proliferate and to extend neurites, but is not a long-term survival factor. Neuron 1:783-790

22. Damon DH, D'Amore PA, Wagner JA 1990 Nerve growth factor and fibroblast growth factor regulate neurite outgrowth and gene expression in PC12 cells via both protein kinase C- and cAMP-independent mechanisms. J Cell Biol 110:1333-1339

23. Greenberg ME, Greene LA, Ziff EB 1985 Nerve growth factor and epidermal growth factor induce rapid transient changes in proto-oncogene transcription in PC12 cells. J Biol Chem 260:14101-14110

24. Byrd JC, Naranjo JR, Lindberg I 1987 Proenkephalin gene expression in the PC12 pheochromocytoma cell line: stimulation by sodium butyrate. Endocrinology 121:1299-1305

25. Lewis EJ, Tank AW, Weiner N, Chikaraishi DM 1983 Regulation of tyrosine hydroxylase mRNA by glucocorticoid and cyclic AMP in a rat pheochromocytoma cell line. Isolation of a cDNA clone for tyrosine hydroxylase mRNA. J Biol Chem 258:14632-14637

26. Ebert SN, Lindley SE, Bengoechea TG, Bain D, Wong DL 1997 Adrenergic differentiation potential in PC12 cells: influence of sodium butyrate and dexamethasone. Brain Res Mol Brain Res 47:24-30

27. Joshi J, Sabol SL 1991 Proenkephalin gene expression in C6 rat glioma cells: potentiation of cyclic adenosine 3',5'-monophosphate-dependent transcription by glucocorticoids. Mol Endocrinol 5:1069-1080

28. Fader D, Lewis EJ 1990 Interaction of cyclic AMP and cell-cell contact in the control of tyrosine hydroxylase RNA. Brain Res Mol Brain Res 8:25-29

29. Ross ME, Evinger MJ, Hyman SE, Carroll JM, Mucke L, Comb M, Reis DJ, Joh TH Goodman HM 1990 Identification of a functional glucocorticoid response element in the phenylethanolamine $\mathrm{N}$-methyltransferase promoter using fusion genes introduced into chromaffin cells in primary culture. J Neurosci 10:520-530

30. McMahon A, Sabban EL 1992 Regulation of expression of dopamine betahydroxylase in PC12 cells by glucocorticoids and cyclic AMP analogues. J Neurochem 59:2040-2047

31. Bradford MM 1976 A rapid and sensitive method for the quantitation of microgram quantities of protein utilizing the principle of protein-dye binding. Anal Biochem $72: 248-254$
32. Seed B, Sheen JY 1988 A simple phase-extraction assay for chloramphenicol acyltransferase activity. Gene 67:271-277

33. DeCristofaro JD, LaGamma EF 1994 Neonatal stress: effects of hypoglycemia and hypoxia on adrenal tyrosine hydroxylase gene expression. Pediatr Res 36:719-723

34. Yoshikawa K, Williams C, Sabol SL 1984 Rat brain preproenkephalin mRNA. cDNA cloning, primary structure, and distribution in the central nervous system. J Biol Chem 259:14301-14308

35. Piechaczyk M, Blanchard JM, Marty L, Dani C, Panabieres F, El Sabouty S, Fort P, Jeanteur P 1984 Post-transcriptional regulation of glyceraldehyde-3-phosphatedehydrogenase gene expression in rat tissues. Nucleic Acids Res 12:6951-6963

36. Byrd JC, Alho H 1987 Differentiation of PC12 pheochromocytoma cells by sodium butyrate. Brain Res 428:151-155

37. Naranjo JR, Mellstrom B, Auwerx J, Mollinedo F, Sassone-Corsi P 1990 Unusual c-fos induction upon chromaffin PC12 differentiation by sodium butyrate: loss of fos autoregulatory function. Nucleic Acids Res 18:3605-3610

38. Goldstein S, Fordis CM, Howard BH 1989 Enhanced transfection efficiency and improved cell survival after electroporation of G2/M-synchronized cells and treatment with sodium butyrate. Nucleic Acids Res 17:3959-3971

39. Gorman CM, Howard BH, Reeves R 1983 Expression of recombinant plasmids in mammalian cells is enhanced by sodium butyrate. Nucleic Acids Res 11:7631-7648

40. Craviso GL, Hemelt VB, Waymire JC 1992 Nicotinic cholinergic regulation of tyrosine hydroxylase gene expression and catecholamine synthesis in isolated bovine adrenal chromaffin cells. J Neurochem 59:2285-2296

41. Gueorguiev VD, Zeman RJ, Hiremagalur B, Menezes A, Sabban EL 1999 Differing temporal roles of $\mathrm{Ca} 2+$ and cAMP in nicotine-elicited elevation of tyrosine hydroxylase mRNA. Am J Physiol 276:C54-C65

42. Gueorguiev VD, Zeman RJ, Meyer EM, Sabban EL 2000 Involvement of alpha7 nicotinic acetylcholine receptors in activation of tyrosine hydroxylase and dopamine beta-hydroxylase gene expression in PC12 cells. J Neurochem 75:1997-2005

43. Hiremagalur B, Nankova B, Nitahara J, Zeman R, Sabban EL 1993 Nicotine increases expression of tyrosine hydroxylase gene. Involvement of protein kinase A-mediated pathway. J Biol Chem 268:23704-23711

44. Tang K, Wu H, Mahata SK, Taupenot L, Rozansky DJ, Parmer RJ, O'Connor DT 1996 Stimulus-transcription coupling in pheochromocytoma cells. Promoter regionspecific activation of chromogranin a biosynthesis. J Biol Chem 271:28382-28390

45. Wang X, Bacher B, Hollt V 1994 Nicotine-induced gene expression of proenkephalin in bovine chromaffin cells. Clin Investig 72:925-929

46. Weidle UH, Grossmann A 2000 Inhibition of histone deacetylases: a new strategy to target epigenetic modifications for anticancer treatment. Anticancer Res 20:14711485

47. Marks PA, Richon VM, Rifkind RA 2000 Histone deacetylase inhibitors: inducers of differentiation or apoptosis of transformed cells. J Natl Cancer Inst 92:1210-1216

48. Cryer PE 2001 Hypoglycemia-associated autonomic failure in diabetes. Am J Physiol 281:E1115-E1121

49. Sivitz WI, Herlein JA, Morgan DA, Fink BD, Phillips BG, Haynes WG 2001 Effect of acute and antecedent hypoglycemia on sympathetic neural activity and catecholamine responsiveness in normal rats. Diabetes 50:1119-1125

50. Tuominen RK, McMillian MK, Ye H, Stachowiak MK, Hudson PM, Hong JS 1992 Long-term activation of protein kinase $\mathrm{C}$ by nicotine in bovine adrenal chromaffin cells. J Neurochem 58:1652-1658

51. Tang K, Wu H, Mahata SK, Mahata M, Gill BM, Parmer RJ, O'Connor DT 1997 Stimulus coupling to transcription versus secretion in pheochromocytoma cells. Convergent and divergent signal transduction pathways and the crucial roles for route of cytosolic calcium entry and protein kinase C. J Clin Invest 100:1180-1192

52. Tang K, Wu H, Mahata SK, O'Connor DT 1998 A crucial role for the mitogenactivated protein kinase pathway in nicotinic cholinergic signaling to secretory protein transcription in pheochromocytoma cells. Mol Pharmacol 54:59-69

53. LaGamma EF, Adler JE, Black IB 1984 Impulse activity differentially regulates [Leu]enkephalin and catecholamine characters in the adrenal medulla. Science 224:1102-1104

54. Cummings JH, Pomare EW, Branch WJ, Naylor CP, Macfarlane GT 1987 Short chain fatty acids in human large intestine, portal, hepatic and venous blood. Gut 28:12211227

55. Heerdt BG, Houston MA, Augenlicht LH 1994 Potentiation by specific short-chain fatty acids of differentiation and apoptosis in human colonic carcinoma cell lines. Cancer Res 54:3288-3293

56. Heerdt BG, Houston MA, Augenlicht LH 1997 Short-chain fatty acid-initiated cell cycle arrest and apoptosis of colonic epithelial cells is linked to mitochondrial function. Cell Growth Differ 8:523-532

57. Heerdt BG, Houston MA, Anthony GM, Augenlicht LH 1998 Mitochondrial membrane potential (delta psi $(\mathrm{mt})$ ) in the coordination of $\mathrm{p} 53$-independent proliferation and apoptosis pathways in human colonic carcinoma cells. Cancer Res 58:2869-2875

58. Mariadason JM, Corner GA, Augenlicht LH 2000 Genetic reprogramming in pathways of colonic cell maturation induced by short chain fatty acids: comparison with trichostatin A, sulindac, and curcumin and implications for chemoprevention of colon cancer. Cancer Res 60:4561-4572

59. Fitch MD, Fleming SE 1999 Metabolism of short-chain fatty acids by rat colonic mucosa in vivo. Am J Physiol 277:G31-G40

60. Liakopoulou E, Blau CA, Li Q, Josephson B, Wolf JA, Fournarakis B, Raisys V, Dover G, Papayannopoulou T, Stamatoyannopoulos G 1995 Stimulation of fetal hemoglobin production by short chain fatty acids. Blood 86:3227-3235

61. Pearson HA 1996 Pharmacologic manipulation of fetal hemoglobin levels in sickle cell diseases and thalassemia: promise and reality. Adv Pediatr 43:309-334

62. Storer G, Trimble R, RJIllman, Snoswell A, Topping D 1983 Effects of dietary oat brain and diabetes on plasma and caecal volatile fatty acids in the rat. Nutr Res $3: 519-526$ 